\title{
Hookworm infection in Amassoma Community in the Niger Delta, Nigeria
}

\author{
* AGI, P.I; AWI-WAADU, G.D.B.
}

Department of Animal \& Environmental Biology, University of Port Harcourt PMB 5323. Port Harcourt

\begin{abstract}
Studies on hookworm infection was conducted in Amassoma community, in the Niger Delta of Nigeria. Of the 4990 faecal samples examined by standard parasitological technique, $1740(34.9 \%)$ samples were found to contain eggs of hookworm. Nine hundred and seventy five infected samples (33.6\%) were males and 865 $(36.7 \%)$ infected samples were females. Incidence or new cases of hookworm infection occurred every month. Highest incidence (12.2\%) occurred in September and the lowest (1.8\%) was in February. The high soil moisture and temperature of the study area were probably responsible for the rapid larval development and infectivity all round the year. Percentage new infection was highest (1.5\%) in the 4-9 years old. Peak prevalence of hookworm infection $(38.5 \%)$ and peak intensity (3000 e pg) occurred in 4-9 years age group. Both prevalence and intensity declined gradually with increase in age. The study demonstrated that the best time for intervention of hookworm transmission is February when incidence is lowest. Also the age group for targeted mass chemotherapy is the 4-9 years old, which had the highest prevalence, incidence and intensity of hookworm infection. This study provides baseline data on the epidemiology of hookworm infection in the Niger Delta. @ JASEM
\end{abstract}

Hookworm infection is a phenomenon of underdevelopment and occurs in Africa, Asia and Latin America. In these areas, the infection rate is over $700-900$ million people with a death toll of $500-600$ thousand people (Shetty and Shetty, 1993). Combs and Crompton (1991) noted that hookworm infection contributed significantly to iron deficiency anaemia. Infection with hookworm occurs when the soil becomes contaminated with faeces carrying hookworm eggs (Oyerinde, 1982). Rural communities are most heavily infected mainly because of indiscriminate faecal deposition and ignorance of health rules. A study of human hookworm distribution in Nigeria shows consistent high infections in both urban slum and rural communities (Obianime, 1977, Oyerinde, 1978, Udonsi; et al., 1980). Apart from the human factors involved in hookworm transmission, rainfall patterns and high tropical temperatures constitute the independent variables enhancing sustained infection (Shetty and Shetty, 1993). In the tropics, hookworm infection is known to flourish where poverty and malnutrition prevail. (Crompton and Whitehead, 1993). Ancylostomasis in Nigeria is caused by Necator americanus and Ancylostoma duodenale (Oyerinde, 1978; Udonsi et al., 1980). Comparatively higher infection rate has been observed for $N$. americanus in all the endemic communities (Oynerinde, 1978). There is however, a gradual increase in $A$. duodenale density in mixed infections toward the Niger Delta coastal communities from the hinterland (Undonsi et al., 1980; Udonsi, 1984). Available literature shows a single investigation of hookworm infection in the Niger Delta conducted in a semi urban community near Port Harcourt (Udonsi, 1984). The present study was conducted as a follow-up and gives fundamental information on the pattern of hookworm infection in a rural setting of a Niger Delta community.

\section{MATERIALS AND METHODS}

\section{The Study area}

The study was carried out in Amassoma community situated $60 \mathrm{~km}$ from Yenagoa, the state capital of Bayelsa State, Nigeria. Amassoma is an important ancient Ijaw town and has a persistent rural outlook and lifestyle. The vegetation is freshwater swampy forest. It has a mean annual rainfall of $3800 \mathrm{~mm}^{3}$ (Kinako, et al., 1989). Relative humidity is $83 \%$ and the soil is freshwater alluvial type with a high capacity for water retention. Mean altitude is $4 \mathrm{~m}$ (asl). Local fishing and farming are the two main occupations. The males have a bent in fishing. Major food crops are plantain and cassava which are processed and consumed in a variety of ways. Living houses are linear and are constructed with wooden materials, mud or concrete. Roofs consist of locally produced materials or corrugated iron sheets. Buildings lack toilet facilities and defaecation therefore is indiscriminate, being littered around the homes, roadsides and in the water bodies from where domestic water is obtained.

\section{Sampling Technique}

Collection of stool samples was carried out between November 2003 and December 2004, in the 5 villages constituting Amassoma community. All the households in each village were numbered serially and only households with odd numbers were sampled. Each member of the household with an odd number was encouraged to submit about $2 \mathrm{~g}$ of early morning faecal material in a sample container which was distributed previously. All the samples collected each day were fixed on the spot using $10 \%$ formalin in the ratio of 1:3. The mixture was thoroughly 
crushed with a glassrod and transported to the laboratory for microscopic examination. For prevalence studies, 4990 faecal samples were collected between November and December 2003. And for incidence studies, faecal samples were collected only from those who were not initially infected during the prevalence studies. Collection of samples for the incidence studies was done once a month between January and December 2004. Candidates who were found infected in any month were not required to submit samples again, in the subsequent months. Name, age, gender and occupation of each participant were obtained through oral interview during submission of samples.

\section{LABORATORY EXAMINATION}

One gramme of faecal sample was weighed out using buckner balance and transferred to a tube containing $10 \mathrm{~cm}^{3}$ of normal saline. The suspension was subjected to a sieve with 0.025 mesh size to remove faecal debris. The suspension was further centrifuged at $1500 \mathrm{rpm}$ for 3 minutes and the floating detritus and excess fluid were decanted leaving a pellet of concentrated faecal matter in the bottom of the tube. Smears of the concentrated faecal matter were placed on the slide and stained with $1 \%$ lugol iodine solution. It was covered using a cover slip and examined under a stereoscopic microscope (Hall, 1981).Intensity of infection was determined by
Stoll's egg dilution technique described by Croll et al (1982).

\section{RESULTS AND DISCUSSION}

Of the 4990 faecal specimens, 1740 (34.9\%) were infected with hookworm (Table 1). Percentage infection of females $(36.7 \%)$ was higher than that of the males $(33.6 \%)$ but not statistically significant $(\mathrm{P}>0.5)$. High infections were observed in all the age categories but these tended to decrease gradually with increase in age. The highest infection (38.5\%) occurred in the 4-9 years age group while the lowest was observed in the $46^{+}$years old. Table 2 displays the number $(\%)$ of new infections (incidence rates) occurring every month. Peak incidence (12.3\%) occurred in September. High incidence rates were observed between June and September. The lowest incidence rate $(1.8 \%)$ occurred in February. New infections occurred in all the months of the year with an annual incidence rate of $6.6 \%$. Table 3 shows hookworm infection in relation to educational/occupational groups as follows: Primary school children $(39.2 \%)$, secondary students $(34.8 \%)$, farmers $(33.0 \%)$ and fishermen $(25.8 \%)$. Candidates in the 4-9 years had the highest mean intensity of 3000 epg. The lowest intensity of infection was observed in the $46^{+}$years old. Both indices of morbidity gradually declined with increase in age (Fig. 1)

\begin{tabular}{|c|c|c|c|c|c|c|c|}
\hline \multirow[t]{2}{*}{$\begin{array}{c}\text { Age In } \\
\text { Years }\end{array}$} & \multicolumn{2}{|c|}{$\begin{array}{c}\text { Number } \\
\text { Examined }\end{array}$} & \multirow[t]{2}{*}{ Total } & \multicolumn{2}{|c|}{ Number infected } & \multirow{2}{*}{ Total } & \multirow[t]{2}{*}{$\begin{array}{c}\text { Overall \% } \\
\text { Infection }\end{array}$} \\
\hline & $\mathrm{M}$ & $\mathrm{F}$ & & M (\%) & $\mathrm{F}(\%)$ & & \\
\hline $4-9$ & 665 & 514 & 1179 & $\begin{array}{c}269 \\
(40.5)\end{array}$ & $\begin{array}{c}185 \\
(36.0)\end{array}$ & 454 & 38.5 \\
\hline $10-15$ & 718 & 555 & 1273 & $\begin{array}{c}256 \\
(35.7)\end{array}$ & $\begin{array}{c}186 \\
(33.5)\end{array}$ & 442 & 35.0 \\
\hline $18-21$ & 482 & 325 & 807 & $\begin{array}{c}160 \\
(33.2)\end{array}$ & $\begin{array}{c}123 \\
(37.8)\end{array}$ & 283 & 35.1 \\
\hline $22-27$ & 316 & 246 & 562 & $\begin{array}{c}88 \\
(27.8)\end{array}$ & $\begin{array}{c}96 \\
(39.0)\end{array}$ & 184 & 32.1 \\
\hline $28-33$ & 279 & 187 & 466 & $\begin{array}{c}84 \\
(30.1)\end{array}$ & $\begin{array}{c}74 \\
(39.6)\end{array}$ & 154 & 33.9 \\
\hline $34-39$ & 141 & 141 & 355 & $\begin{array}{c}64 \\
(29.9)\end{array}$ & $\begin{array}{c}55 \\
(39.0)\end{array}$ & 119 & 33.5 \\
\hline $40-45$ & 142 & 64 & 207 & $\begin{array}{c}37 \\
(25.9)\end{array}$ & $\begin{array}{c}27 \\
(42.0)\end{array}$ & 64 & 30.9 \\
\hline $46^{+}$ & 86 & 55 & 141 & $\begin{array}{c}17 \\
(19.8) \\
\end{array}$ & $\begin{array}{c}19 \\
(34.5) \\
\end{array}$ & 36 & 25.5 \\
\hline Total & 2903 & 087 & 4990 & $\begin{array}{c}975 \\
(33.6)\end{array}$ & $\begin{array}{c}765 \\
(36.7)\end{array}$ & 1740 & 34.9 \\
\hline
\end{tabular}

\footnotetext{
* Corresponding author: Agi P. I.
} 
Table 2: Monthly incidence of hookworm infection in Amassoma community by age category

\begin{tabular}{|c|c|c|c|c|c|c|c|c|c|c|c|}
\hline \multirow[t]{2}{*}{ Month } & \multirow{2}{*}{$\begin{array}{l}\text { Number of } \\
\text { Uninfected } \\
\text { case examine }\end{array}$} & \multicolumn{8}{|c|}{ Age ( in years) } & \multirow[t]{2}{*}{ Total } & \multirow{2}{*}{$\begin{array}{l}\text { Overall } \\
\text { percentage }\end{array}$} \\
\hline & & $4-9$ & $10-15$ & $16-21$ & $22-27$ & $28-33$ & $34-39$ & $40-45$ & $6+$ & & \\
\hline Jan & 194 & 2 & 1 & 1 & 1 & - & 1 & 1 & - & 7 & 3.6 \\
\hline Feb & 166 & 1 & 1 & 1 & 1 & - & - & - & - & 3 & 1.8 \\
\hline Mar & 165 & 2 & 2 & 1 & - & 1 & 1 & 1 & 1 & 9 & 5.5 \\
\hline Apr & 141 & 2 & 2 & 2 & 1 & 1 & 1 & - & - & 10 & 7.0 \\
\hline May & 127 & 2 & 1 & 1 & 2 & 2 & 1 & 1 & - & 10 & 7.9 \\
\hline June & 93 & 2 & 1 & 2 & 1 & 1 & 1 & 1 & - & 9 & 9.8 \\
\hline Jul & 84 & 2 & 2 & 1 & 1 & 1 & - & 1 & 1 & 9 & 10.7 \\
\hline Aug & 86 & 2 & 1 & 1 & - & 1 & - & - & 1 & 6 & 9.1 \\
\hline Sept & 65 & 2 & 1 & 1 & - & 1 & 1 & 1 & 1 & 8 & 12.3 \\
\hline Oct & 61 & 1 & 2 & 1 & - & 1 & - & - & 1 & 6 & 9.8 \\
\hline Nov & 52 & 1 & 2 & - & - & 1 & - & 1 & - & 4 & 7.7 \\
\hline Dec & 67 & 1 & 1 & 1 & - & - & - & - & - & 3 & 4.5 \\
\hline Total $(\%)$ & 1281 & $\begin{array}{l}19 \\
(1.5)\end{array}$ & $\begin{array}{l}16 \\
(1.2)\end{array}$ & $\begin{array}{l}13 \\
(1.0)\end{array}$ & $\begin{array}{l}7 \\
(0.5)\end{array}$ & $\begin{array}{l}10 \\
(0.8)\end{array}$ & $\begin{array}{l}6 \\
(0.5)\end{array}$ & $\begin{array}{l}7 \\
(0.5)\end{array}$ & $\begin{array}{l}6 \\
(0.5)\end{array}$ & $\begin{array}{l}84 \\
(6.6)\end{array}$ & \\
\hline
\end{tabular}

Table 3: Hookworm infection by groups in Amassoma Community

\begin{tabular}{llll}
\hline Occupation & $\begin{array}{l}\text { Number } \\
\text { Examined }\end{array}$ & $\begin{array}{l}\text { Number } \\
\text { Infected }\end{array}$ & $\begin{array}{l}\text { Percentage } \\
\text { Infected }\end{array}$ \\
\hline Primary School pupil & 1958 & 768 & $39.2 \%$ \\
Secondary School Students & 1182 & 411 & $34.8 \%$ \\
Fishermen & 683 & 176 & $25.8 \%$ \\
Farmers & 1167 & 385 & $33.0 \%$ \\
\hline Total & 4990 & 1740 & 34.9 \\
\hline
\end{tabular}

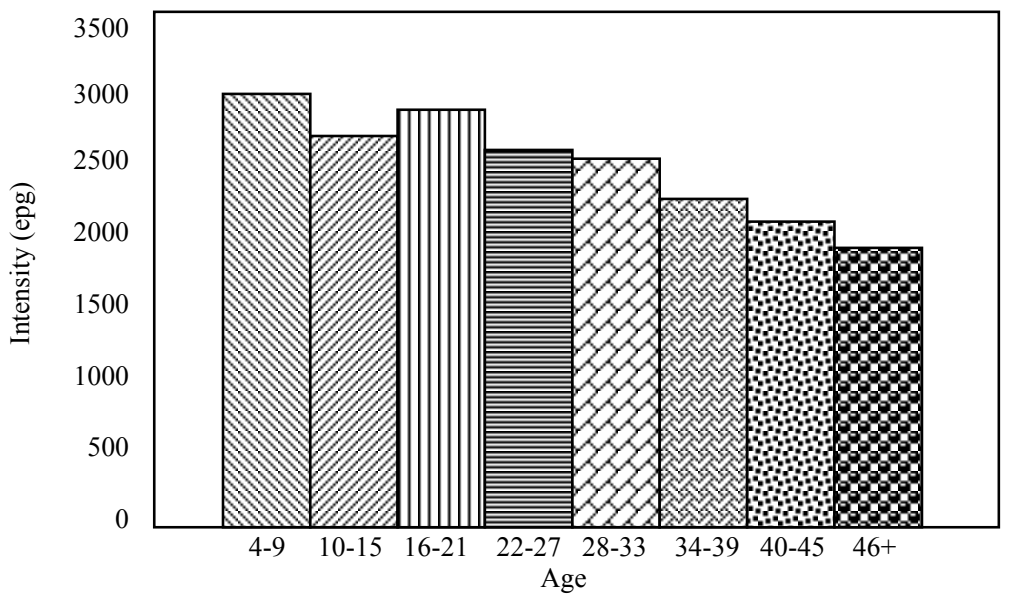

Fig. 1: Mean intensity of hookworm infection in Amassoma community by age category

Two distinct sizes of hook worm eggs were observed. A larger size of eggs measuring between $60-70 \mu \mathrm{m}$ long which were Necator americanus eggs. The smaller size measuring from $47-56 \mu \mathrm{m}$ long were Ancylostoma duodenale eggs. The former eggs belonging to $N$. americnus formed over $70 \%$ of the population when the two hookworms occurred together. Observations on hookworm infection in Amassoma Community provided fundamental data on the epidemiology of hookworm infection in a freshwater swamp forest environment. The overall hookworm infection (34.9\%) in Amassoma was higher than the overall hookworm prevalence $(18.8 \%)$ observed in Bonny, a rural community of the mangrove forest zone of the Niger Delta (Agi,1997). The disparity was attributed to the saline environment of the marine mangrove ecosystem, which was relatively harsh to the development of a geohelminthic larva. The increasing hookworm prevalence with age in females was indicative of a strong female association with soil through farming activities. The association between soil contact and hookworm infection has been noted by many researchers in Nigeria (Udonsi et al., 1980; Udonsi, 1984; Ejezie, 1983; Nwosu, 1981). Higher hookworm infection in females has been recorded in Isiokpo (Agi, 1997). This is also because more females were exposed to contaminated soils through farming. Albonico et al (1993) observed that "hookworm transmission tends to be focal and very dependent on the local rainfall humidity and soil". Shetty \& Shetty (1993) stated that a wet and humid tropical environment is essential for the life cycle of parasites. Decreasing prevalence of hookworm 
infection with age in the males demonstrated early involvement of male children in farming activities which were later abandoned for fishing after secondary education. Some workers however have noted higher hookworm infection in males (Akogun and Badaki, 1998).

Peak prevalence, incidence and intensity were observed in the 4-9 year-olds. Udonsi (1983) noted that these morbidity indices for ancylostomiasis occurred in the 16-19 years age bracket. Many observations are consistent with the findings of this exercise (Oyerinde, 1978; Idris et al., 1993). Ejezie (1983) noted that hookworm infection is a disease of childhood but Crompton and Whitehead (1993) stated that both prevalence and intensity rose slowly from childhood to adult. Shetty \& Shetty (1993) observed that parasitic infection is focal while Crompton and Whitehead (loc cit.) further noted that heavy infection of hookworm in rural communities was presumably because of their constant contact with soil. We hold the view that the most important factor in the epidemiology of hookworm in the rural tropical environment is the frequency of contact with contaminated soil and not the age of candidate. Mixed population of hookworm was observed in this study by the differential egg size (Oyerinde, 1978). The smaller egg size belonging to Ancylostoma duodenale was encountered less frequently. This observation contradicted an earlier one which stated that, in the Niger Delta, the proportion of $\underline{A}$. duodenale in mixed population with Nector americanus was greater (Udonsi, 1984).

\section{REFERENCES}

Agi, P I (1997). Comparative helminth infections of man in two rural communities of the Niger Delta, Nigeria. W.A.J. M. 16(4): $232-236$.

Akogun, O B; Badaki, J (1998). Intestinal helminth infection in two communities along the Benue river valley, Adamawa State Nigeria. Nig. J. Parasit 19(1): $67-72$.

Albonico, M; de Carneri, J; di Matteo L; Ghiglietti, R; Toscano, P; Uledi, M.K.; Savioli, L. (1993). Intestinal parasitic infections of urban and rural children on Pemb Island: Implications for control. Ann. Trop. Med. Parasit 87(6): 579 583.

Coombs, L; Crompton, D W T (1991) A guide to Human Helminths, Taylor \& Francis Ltd, London.

Croll, N A; Anderson, R.M; Cyorkos, T W; Ghadirian, E (1982). The population biology and control of Ascaris lumbricoides in a rural community in Iran. Trans. R. Soc. Trop. Med. Hyg. 76: $178-193$
Crompton, D W J; Whitehead, R R (1993). Hookworm infections and Human iron metabolism. Parasitol. 107 (Supple): 137-145

Ejezie, G C (1983). The Nigerian environment and parasitic infections. Folia Parasitologica, 30: 89 -95 .

Hall, A (1981). Quantitative variability of nematode egg counts in faeces: A study among rural Kenyans. Trans. R. Soc. Trop. Med. Hyg. 75: $682-687$.

Idris, M A ; Rapel, A; de Carner, I (1993). High prevalence and intensity of hookworm infection in the Dhofar Governorate, Oman. Ann. Trop. Med. Parasit. 87(4): $421-242$.

Kinako, P.D.S., Wilcox-Evwaraye, B.H.E. and Salau, O. (1989). Climate and Vegetation. In: Land and People of Nigeria: Rivers State. Alagoa, E.J. and Tamuno, T.N. (eds), Port Harcourt, Riverside Communications, $31-33$

Nwosu, A B C (1981). The community ecology of soil-transmitted helminth infection of humans in a hyperendemic area of Southern Nigeria. Ann. Trop. Med. Parasit. 75: $198-208$.

Obianime, B A (1977). The pattern of parasitic infection in human gut at the Specialist Hospital, Benin City, Nigeria. Ann. Trop. Med. Parasit. 76: $75-82$

Oyerinde, J P O (1982). Intestinal Helminthic infections of man in Nigeria. Nig. Med. Pract. Suppl. 1:33-48.

Oyerinde, J.P.O. (1978). Human Ancylostoma infections in Nigeria. Ann. Trop. M ed. Parasit. 72: $263-267$.

Shetty, P S ; Shetty, N (1993). Parasitic infection and chronic energy deficiency in adults. Parasit. 107 (supple): 159-167.

Udonsi, J K (1983). Necator Americanus infection: a longitudinal study of an urban area in Nigeria. Ann. Trop. Med. Parasit. 77: $305-310$.

Udonsi, J K (1984). Studies on the Co-occurrence of two species of Human Hookworm in a Riverine Community in Nigeria. Tropemed. Parasit. 35

Udonsi, J K; Nwosu, A B C; Anya, A O (1980). Necator Americanus: Population structure, distribution and fluctuations of population densities of infective larvae in contaminated farmlands. Z. Parasitenkd. 63: 251-259. 